OPEN ACCESS

Edited by:

Guilherme Zweig Rocha, State University of Campinas, Brazil

Reviewed by: Amir Hadi, Isfahan University of Medical

Sciences, Iran Vahidreza Ostadmohammadi, Kashan University of Medical

Sciences, Iran

*Correspondence:

Xiaoling Cai

dr_june/@sina.com

Li Zhang

zhangli@ciss.cn

Linong Ji

jiln@bjmu.edu.cn

Specialty section:

This article was submitted to

Clinical Diabetes,

a section of the journal

Frontiers in Endocrinology

Received: 30 August 2021 Accepted: 28 October 2021 Published: 17 November 2021

Citation:

Zhu X, Zhao L, Chen J, Lin C. LV F, Hu S, Cai $X$, Zhang $L$ and Ji L (2021) The Effect of Physical Activity on Glycemic Variability in Patients With Diabetes: A Systematic

Review and Meta-Analysis of Randomized Controlled Trials.

Front. Endocrinol. 12:767152. doi: 10.3389/fendo.2021.767152

\section{The Effect of Physical Activity on Glycemic Variability in Patients With Diabetes: A Systematic Review and Meta-Analysis of Randomized Controlled Trials}

\author{
Xingyun Zhu ${ }^{1}$, Lina Zhao ${ }^{2}$, Jing Chen ${ }^{1}$, Chu $\mathrm{Lin}^{1}$, Fang $\mathrm{Lv}^{1}$, Suiyuan $\mathrm{Hu}^{1}$, Xiaoling Cai ${ }^{1 *}$, \\ Li Zhang ${ }^{3 *}$ and Linong $\mathrm{Ji}^{1 *}$ \\ ${ }^{1}$ Department of Endocrinology and Metabolism, Peking University People's Hospital, Beijing, China, ${ }^{2}$ Department of \\ Endocrinology and Metabolism, Langfang Traditional Chinese Medicine (TCM) Hospital, Hebei, China, ${ }^{3}$ China Institute of \\ Sport Science, Beijing, China
}

Purpose: The effect of physical activity on glycemic variability remains controversial. This meta-analysis aimed to assess the overall effect of physical activity treatment on glycemic variability in patients with diabetes.

Methods: PubMed/MEDLINE, Embase, and Cochrane databases were searched for clinical trials that conducted in patients with type 1 diabetes mellitus and type 2 diabetes mellitus with reports of the mean amplitude of glycemic excursion (MAGE), time in range (TIR), time above range (TAR), or time below range (TBR). Eligible trials were analyzed by fixed-effect model, random effect model, and meta-regression analysis accordingly.

Results: In total, thirteen trials were included. Compared with the control group, physical activity intervention was significantly associated with increased TIR (WMDs, 4.17\%; 95\% Cl, 1.11 to $7.23 \%, P<0.01$ ), decreased MAGE (WMDs, $-0.68 \mathrm{mmol} / \mathrm{L} ; 95 \% \mathrm{Cl},-1.01$ to -0.36 $\mathrm{mmol} / \mathrm{L}, \mathrm{P}<0.01$ ) and decreased TAR (WMDs, $-3.54 \%$; $95 \% \mathrm{Cl},-5.21$ to $-1.88 \%, \mathrm{P}<0.01$ ) in patients with diabetes, but showed insignificant effects on TBR. Patients with higher baseline BMl levels was associated with a greater decrease in MAGE $(\beta=-0.392,95 \% \mathrm{Cl}$ : $-0.710,-0.074$ ), and patients with lower baseline $\mathrm{HbA} 1 \mathrm{c}$ levels was associated with a greater increase in TBR during physical activities ( $\beta=-0.903,95 \% \mathrm{Cl}:-1.550,-0.255)$.

Conclusion: Physical activity was associated with significantly decreased glycemic variability in patients with diabetes. Patients with higher BMl might benefit more from physical activity therapy in terms of a lower MAGE. Hypoglycemia associated with physical activity treatment still warranted caution, especially in patients with intensive glycemic control.

Systematic Review Registration: PROSPERO [CRD42021259807].

Keywords: physical activity, glycemic variability, glycemic control, diabetes, continuous glucose monitoring 


\section{INTRODUCTION}

Physical activity was considered as an easy and economical way to improve overall well-being $(1,2)$. In previous studies, physical activity was proved to improve glycemic control, manifested as reducing hemoglobin $\mathrm{Alc}(\mathrm{HbAlc})$ and fasting plasma glucose (FPG) (3-6). Recent studies indicated that even light physical activities breaking the prolonged sitting could bring metabolic benefits to patients with diabetes $(7,8)$. Hence, physical activity was recognized as a key non-pharmaceutical strategy for patients with diabetes in most international and national guidelines (9-11).

However, the efficacy of physical activity treatment on the improvement of HbAlc could only indicate the reduction in mean glucose level. Whether taking physical activities will expose diabetic patients to an increased risk of hyperglycemia or hypoglycemia is still under great debate $(4,5,12-17)$. Since emerging evidence has built a positive relationship between glycemic variability and diabetes complications, the effect of physical activity on glycemic variability increasingly attracts public attention (18-21).

Accessing glycemic variability was not easy with traditional glucose monitor strategies, including self-monitoring of blood glucose, HbAlc measurement, and glycated albumin measurement. Nevertheless, with the availability of new glucose monitoring technics, especially continuous glucose monitoring (CGM), several computations turned out to be good indicators for glycemic variability. Among those computations, time in range (TIR), time above range (TAR), time below range (TBR), and mean amplitude of glycemic excursion (MAGE) were the most popular indicators for within-day glycemic variability and were wildly discussed in previous researches (22-24).

In this study, we used TIR, TAR, TBR, and MAGE to measure the glycemic variability. The main purpose of this meta-analysis was to evaluate the effect of physical activity treatment on glycemic variability in patients with diabetes.

\section{MATERIALS AND METHODS}

This meta-analysis was conducted according to the Cochrane Handbook for Systematic Reviews of Interventions (25). A PRISMA (Preferred Reporting Items for Systematic Reviews and Meta-Analyses) checklist was created and showed in the Supplementary Materials. The study was previously registered on PROSPERO with ID CRD42021259807.

\section{Data Sources and Searches}

According to the Cochrane Handbook (25), one investigator (Xingyun Zhu) performed the systematic searches in EMBASE,

\footnotetext{
Abbreviations: CGM, continuous glucose monitoring; TIR, time in range; TAR, time above range; TBR, time below range; MAGE, mean amplitude of glycemic excursion; RCTs, Random controlled trials; WMDs, weighted mean differences; CI, confidence intervals; HbAlc, Hemoglobin Alc; BMI, body mass index; T1DM, type 1 diabetes; T2DM, type 2 diabetes.
}

MEDLINE (accessed by PubMed), and Cochrane Central Register of Controlled Trials for studies of physical activity intervention published between January 1980 and October 2021. The searching terms were as follows: "Exercise", "Physical Activity", "Circuit-Based Exercise", "Cool-Down Exercise", "Warm-Up Exercise", "Exercise Movement Techniques", "Exercise Therapy", "Exercise Test", "Resistance Training", "Muscle Stretching Exercises", "High-Intensity Interval Training", "Diabetes Mellitus", "Diabetes", "Diabetes Mellitus", "Randomized Controlled Trial", "Randomized Controlled Trials", "Controlled Clinical Trial", "Continuous Glucose Monitoring". The full electronic search strategy was shown in Supplementary Table S1.

\section{Study Selection}

The inclusion criteria for the meta-analysis were as follows: 1) Random controlled trials (RCTs) conducted in people with type 1 diabetes or type 2 diabetes. 2) RCTs that had at least one arm of physical activity intervention, compared with a no-exercise control group. 3) RCTs that monitored glucose variation with CGM. 4) RCTs with the reported result of any of the following as outcome variables: MAGE, TIR, TAR, TBR. The exclusion criteria for the meta-analysis were as follows: 1) RCTs conducted in patients with gestational diabetes, other special types of diabetes, or without diabetes. 2) Trials conducted in animal models. 3) Duplicate publications. 4) Reviews. In this study, physical activity was defined as any intervention that breaks prolong sitting.

\section{Data Extraction and Quality Assessment}

Two investigators (Xingyun Zhu and Lina Zhao) independently collected data of all studies, including publication details, population characteristics, physical activities, results of TIR, TAR, TBR, MAGE, etc. Definitions of hyperglycemia and hypoglycemia were also recorded. We invited a third investigator (Chu Lin) to join the discussion and resolved discrepancies by consensus. The risk of bias was evaluated according to the Cochrane risk of bias tool. The quality of the included evidence was evaluated by the GRADE Approach (26).

\section{Data Synthesis and Analysis}

The primary outcome was the changes in TIR and MAGE between the physical activity treatment group and the control group in patients with diabetes. The secondary outcomes included the changes in TAR and TBR between the physical activity treatment group and the control group in patients with diabetes.

Prespecified subgroup analyses were stratified by baseline age, sex, BMI, HbAlc, and disease duration. All the outcomes in analyses were continuous variables and evaluated by computing the weighted mean differences (WMDs) and 95\% confidence intervals (CI). We used Higgins $\mathrm{I}^{2}$ statistics to evaluate betweenstudy heterogeneity, with an $\mathrm{I}^{2}$ value $>50$ indicating a high level of heterogeneity. The prediction intervals of I2 were calculated according to a method described by previous studies $(27,28)$. The fixed-effects model was used for a low level of heterogeneity, and the random-effects model was used for a high level of 
heterogeneity. We used the $\mathrm{Z}$ test to compare the mean difference of effect sizes between subgroups. Meta-regression analyses were conducted to evaluate the associations between different potential influencing indicators (including age, sex, disease duration, baseline HbA1c level, body mass index) in outcomes. Publication bias was assessed via the Beggs test and funnel plot. Statistical significance was considered at $P<0.05$.

\section{RESULTS}

\section{Study Selection, Study Characteristics, and Quality Assessment}

In total, 13 RCTs were included in this meta-analysis. Among all included trials, 11 were studies with crossover design, and 2 were studies with parallel design. Figure 1 summarized the selection process of included studies. Baseline characteristics of each included RCT were shown in Table 1. The descriptions of exercise in RCTs were summarized in the supplementary material (Supplementary Table S2). The overall risk of bias and selective reporting bias was low, and no significant publication bias was found (Supplementary Table S3 and Supplementary Figures S1, S2). According to the GRADE Approach, the quality of included trials in included outcomes was ranked low to moderate (Supplementary Table S4).

\section{The Effect of Physical Activity on the TIR}

Compared with the control group, patients that took physical activity had significantly higher TIR (WMDs, 4.17\%; 95\% CI, 1.11 to $\left.7.23 \%, P<0.01, \mathrm{I}^{2}=0 \%\right)$. In patients with type 2 diabetes, compared with the control group, TIR was significantly increased in patients with physical activity treatment (WMDs,
$4.21 \%$; $95 \%$ CI, 0.95 to $\left.7.46 \%, P<0.01, \mathrm{I}^{2}=0 \%\right)$. However, in patients with type 1 diabetes, TIR was not significantly different between groups (Table 2 and Supplementary Figure S3).

\section{The Effect of Physical Activity on the MAGE}

Overall, compared with the control group, physical activity led to significant reductions in MAGE in patients with type 2 diabetes (WMDs, $-0.68 \mathrm{mmol} / \mathrm{L}$; $95 \% \mathrm{CI},-1.01$ to $-0.36 \mathrm{mmol} / \mathrm{L}, P<0.01$, $\mathrm{I}^{2}=78 \%$ ) (Table 2 and Supplementary Figure S4).

Compared with the control group, MAGE was significantly decreased in patients with baseline $\mathrm{HbAlc} \geq 7 \%$ in the physical activity group (WMDs, $-1.13 \mathrm{mmol} / \mathrm{L} ; 95 \% \mathrm{CI},-1.44$ to -0.82 , $P<0.01, \mathrm{I}^{2}=52 \%$ ), but not in patients with baseline $\mathrm{HbA} 1 \mathrm{c}<7 \%$ in the physical activity group. When stratified by baseline BMI level, compared with the control group, MAGE was significantly decreased in patients with $\mathrm{BMI} \geq 30 \mathrm{~kg} / \mathrm{m}^{2}$ in the physical activity group (WMDs, $-1.08 \mathrm{mmol} / \mathrm{L}$; $95 \% \mathrm{CI},-1.45$ to $-0.71, P<0.01$, $\mathrm{I}^{2}=68 \%$ ), as well as in patients with $\mathrm{BMI}<30 \mathrm{~kg} / \mathrm{m}^{2}$ in physical activity group (WMDs, $-0.44 \mathrm{mmol} / \mathrm{L} ; 95 \% \mathrm{CI},-0.82$ to -0.06 , $\left.P<0.01, \mathrm{I}^{2}=0 \%\right)$. When compared with the control group, a significant decrease in MAGE was revealed in patients with shorter disease duration in the physical activity group (WMDs, $-1.13 \mathrm{mmol} / \mathrm{L}$; $95 \% \mathrm{CI},-1.44$ to $-0.82, P<0.01, \mathrm{I}^{2}=58 \%$ ), but was not observed in patients with longer disease duration in the physical activity group (Table 2 ).

\section{The Effect of Physical Activity on the TAR and TBR}

Overall, physical activity was associated with significant decrease in TAR (WMDs, $-3.54 \%$; $95 \%$ CI, -5.21 to $-1.88 \%$, $P<0.01, \mathrm{I}^{2}=0 \%$ ) with no effect on TBR (WMDs, $0.36 \%$; $95 \% \mathrm{CI}$,

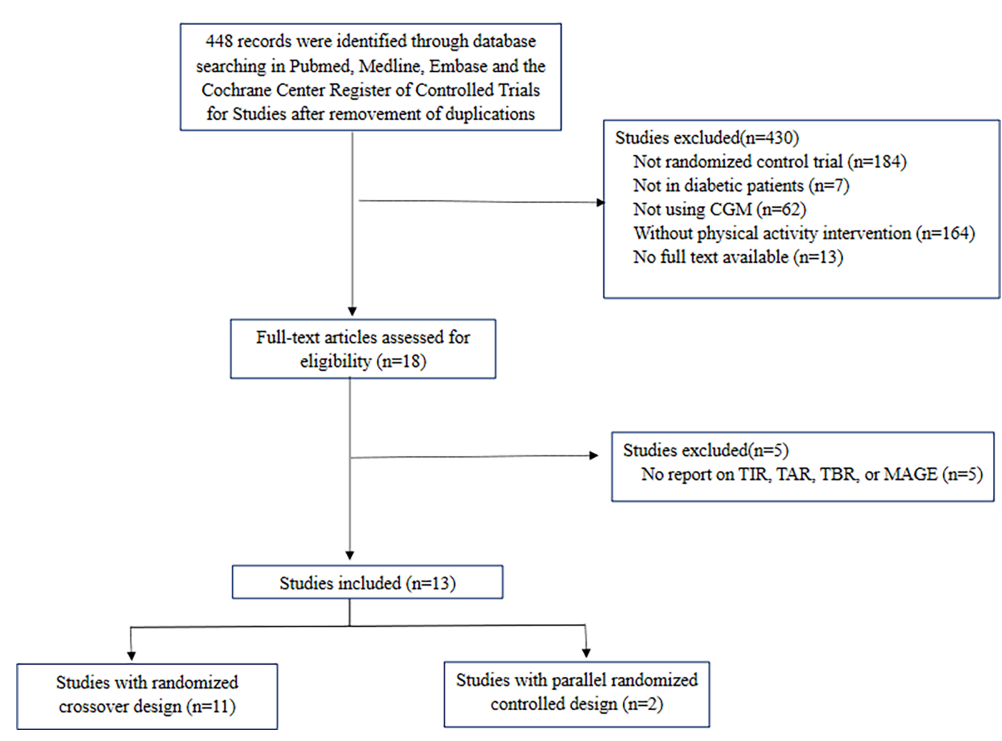

FIGURE 1 | Flow chart of included trials. CGM, continuous glucose monitoring; TIR, time in range; TAR, time above range; TBR, time below range; MAGE, mean amplitude of glycemic excursion. 
TABLE 1 | Baseline characteristics of each included random controlled trials.

\begin{tabular}{|c|c|c|c|c|c|c|c|c|c|c|}
\hline $\begin{array}{l}\text { Author, } \\
\text { year }\end{array}$ & $\begin{array}{l}\text { Exercise } \\
\text { duration }\end{array}$ & Treatment group & $\begin{array}{l}\text { Standard } \\
\text { diet }\end{array}$ & $\begin{array}{c}\text { No. of } \\
\text { patients }\end{array}$ & Age (years) & $\begin{array}{l}\text { Men } \\
(\%)\end{array}$ & $\begin{array}{c}\text { BMI } \\
\left(\mathrm{kg} / \mathrm{m}^{2}\right)\end{array}$ & $\begin{array}{l}\text { Duration of } \\
\text { diabetes } \\
\text { (years) }\end{array}$ & $\begin{array}{c}\text { Baseline } \\
\text { HbA1c (\%) }\end{array}$ & $\begin{array}{c}\text { Definition of } \\
\text { hypoglycemia and } \\
\text { hyperglycemia } \\
\text { (mmol/L) }\end{array}$ \\
\hline \multirow[t]{3}{*}{$\begin{array}{l}\text { Paddy } \\
2017 \text { (29) }\end{array}$} & \multirow[t]{3}{*}{24 hours } & $\begin{array}{l}\text { Light-intensity } \\
\text { walking }\end{array}$ & \multirow[t]{3}{*}{ yes } & 24 & $62 \pm 6$ & 58.3 & $33.0 \pm 3.4$ & $6.8 \pm 5.1$ & $7.2 \pm 0.7$ & \multirow[t]{3}{*}{$\begin{array}{l}3.9 \leq \\
10 \geq\end{array}$} \\
\hline & & $\begin{array}{l}\text { Simple resistance } \\
\text { activities }\end{array}$ & & 24 & $62 \pm 6$ & 58.3 & $33.0 \pm 3.4$ & $6.8 \pm 5.1$ & $7.2 \pm 0.7$ & \\
\hline & & Control & & 24 & $62 \pm 6$ & 58.3 & $33.0 \pm 3.4$ & $6.8 \pm 5.1$ & $7.2 \pm 0.7$ & \\
\hline Jonida & \multirow[t]{3}{*}{ 72hours } & Continuous walking & \multirow[t]{3}{*}{ yes } & 9 & $58.2 \pm 6.6$ & 100 & $30.2 \pm 3.1$ & $5.2 \pm 4.3$ & $7.0 \pm 0.6$ & $\mathrm{NA}$ \\
\hline \multirow[t]{2}{*}{$2015(30)$} & & Split walking & & 9 & $58.2 \pm 6.6$ & 100 & $30.2 \pm 3.1$ & $5.2 \pm 4.3$ & $7.0 \pm 0.6$ & \multirow[t]{2}{*}{$\mathrm{NA}$} \\
\hline & & Control & & 9 & $58.2 \pm 6.6$ & 100 & $30.2 \pm 3.1$ & $5.2 \pm 4.3$ & $7.0 \pm 0.6$ & \\
\hline Jordan & \multirow[t]{2}{*}{6 days } & Exercise & \multirow[t]{2}{*}{ yes } & 63 & $64.4 \pm 8.0$ & 46 & $30.5 \pm 6.5$ & $9.7 \pm 6.1$ & $6.8 \pm 0.7$ & $4 \leq$ \\
\hline 2019 (31) & & Control & & 63 & $64.4 \pm 8.0$ & 46 & $30.5 \pm 6.5$ & $9.7 \pm 6.1$ & $6.8 \pm 0.7$ & $10 \geq$ \\
\hline \multirow{2}{*}{$\begin{array}{l}\text { Zheng Li } \\
2018 \text { (32) }\end{array}$} & \multirow[t]{2}{*}{ 2days } & Exercise & \multirow[t]{2}{*}{ yes } & 29 & $51 \pm 11.2$ & 75.9 & $24.8 \pm 3.4$ & $5.7 \pm 6.0$ & $7.3 \pm 1.3$ & $\mathrm{NA}$ \\
\hline & & Control & & 29 & $51 \pm 11.2$ & 75.9 & $24.8 \pm 3.4$ & $5.7 \pm 6.0$ & $7.3 \pm 1.3$ & $\mathrm{NA}$ \\
\hline \multirow[t]{4}{*}{$\begin{array}{l}\text { Richard } \\
2018 \text { (33) }\end{array}$} & \multirow[t]{4}{*}{ 3days } & $\begin{array}{l}\text { Reduced-exertion } \\
\text { high-intensity interval } \\
\text { training (REHIT) }\end{array}$ & \multirow[t]{4}{*}{ yes } & 11 & $52 \pm 6$ & 100 & $29.7 \pm 3.1$ & $4 \pm 3$ & $7.0 \pm 0.8$ & \multirow[t]{4}{*}{$\begin{array}{l}\mathrm{NA} \\
9 \geq\end{array}$} \\
\hline & & $\begin{array}{l}\text { Moderate-vigorous- } \\
\text { intensity continuous } \\
\text { exercise } 30 \text { min } \\
\text { (MICT) }\end{array}$ & & 11 & $52 \pm 6$ & 100 & $29.7 \pm 3.1$ & $4 \pm 3$ & $7.0 \pm 0.8$ & \\
\hline & & $\begin{array}{l}\text { High-intensity } \\
\text { interval training }(\mathrm{HIIT})\end{array}$ & & 11 & $52 \pm 6$ & 100 & $29.7 \pm 3.1$ & $4 \pm 3$ & $7.0 \pm 0.8$ & \\
\hline & & Control & & 11 & $52 \pm 6$ & 100 & $29.7 \pm 3.1$ & $4 \pm 3$ & $7.0 \pm 0.8$ & \\
\hline \multirow[t]{3}{*}{$\begin{array}{l}\text { Kristian } \\
2016(34)\end{array}$} & \multirow[t]{3}{*}{2 weeks } & $\begin{array}{l}\text { Continuous walking } \\
\text { training }\end{array}$ & \multirow[t]{3}{*}{ NA } & 14 & $65 \pm 2$ & 78.6 & NA & NA & $6.6 \pm 0.4$ & \multirow[t]{3}{*}{$\begin{array}{c}4 \leq \\
10 \geq\end{array}$} \\
\hline & & $\begin{array}{l}\text { Interval walking } \\
\text { training }\end{array}$ & & 14 & $65 \pm 2$ & 78.6 & NA & NA & $6.5 \pm 0.3$ & \\
\hline & & Control & & 14 & $65 \pm 2$ & 78.6 & NA & NA & $6.6 \pm 0.3$ & \\
\hline \multirow{5}{*}{$\begin{array}{l}\text { Myette-Côté } \\
2015(35) \\
\text { Tasuku } \\
2016(36)\end{array}$} & \multirow[t]{2}{*}{24 hours } & Exercise & \multirow[t]{2}{*}{ yes } & 10 & $59.0 \pm 9.6$ & 50 & $29.5 \pm 4.7$ & $7.7 \pm 5.2$ & NA & $4 \leq$ \\
\hline & & Control & & 10 & $59.0 \pm 9.6$ & 50 & $29.5 \pm 4.7$ & $7.7 \pm 5.2$ & NA & $8 \geq$ \\
\hline & \multirow[t]{3}{*}{24 hours } & $\begin{array}{l}\text { Moderate-intensity } \\
\text { continuous exercise }\end{array}$ & yes & 10 & $60 \pm 6$ & 80.0 & $30.8 \pm 5.4$ & $6.8 \pm 4.6$ & $7.1 \pm 1.0$ & $\begin{array}{c}4 \leq \\
10 \geq\end{array}$ \\
\hline & & $\begin{array}{l}\text { High-intensity } \\
\text { interval exercise }\end{array}$ & & 10 & $60 \pm 6$ & 80.0 & $30.8 \pm 5.4$ & $6.8 \pm 4.6$ & $7.1 \pm 1.0$ & \\
\hline & & Control & & 10 & $60 \pm 6$ & 80.0 & $30.8 \pm 5.4$ & $6.8 \pm 4.6$ & $7.1 \pm 1.0$ & \\
\hline $\begin{array}{l}\text { Jennifer } \\
2018(37)\end{array}$ & 24hours & $\begin{array}{l}\text { Morning walk after } \\
\text { breakfast }\end{array}$ & yes & 30 & $64 \pm 8.2$ & 46.7 & $31.7 \pm 5.4$ & $10 \pm 7.8$ & $7.4 \pm 1.1$ & $\begin{array}{l}\mathrm{NA} \\
10 \geq\end{array}$ \\
\hline & & $\begin{array}{l}\text { Post-meal breaks } \\
\text { from sitting }\end{array}$ & & 30 & $64 \pm 8.2$ & 46.7 & $31.7 \pm 5.4$ & $10 \pm 7.8$ & $7.4 \pm 1.1$ & \\
\hline & & Control & & 30 & $64 \pm 8.2$ & 46.7 & $31.7 \pm 5.4$ & $10 \pm 7.8$ & $7.4 \pm 1.1$ & \\
\hline Matthew & 12 days & Morning Exercise & yes & 14 & $65 \pm 9.0$ & 57.1 & $27.2 \pm 3.5$ & $10.5 \pm 6.7$ & $6.7 \pm 0.6$ & $4 \leq$ \\
\hline $2020(38)$ & & Afternoon Exercise & & 14 & $65 \pm 9.0$ & 57.1 & $27.2 \pm 3.5$ & $10.5 \pm 6.7$ & $6.7 \pm 0.6$ & $10 \geq$ \\
\hline & & Evening Exercise & & 14 & $65 \pm 9.0$ & 57.1 & $27.2 \pm 3.5$ & $10.5 \pm 6.7$ & $6.7 \pm 0.6$ & \\
\hline & & Control & & 14 & $65 \pm 9.0$ & 57.1 & $27.2 \pm 3.5$ & $10.5 \pm 6.7$ & $6.7 \pm 0.6$ & \\
\hline Ravi & 3weeks & Aerobic exercise & yes & 10 & $33 \pm 6$ & 40.0 & $24.4 \pm 2.1$ & $18 \pm 10$ & $7.4 \pm 1$ & $3.9 \leq$ \\
\hline 2018 (39) & & Resistance exercise & & 10 & $33 \pm 6$ & 40.0 & $24.4 \pm 2.1$ & $18 \pm 10$ & $7.4 \pm 1$ & $10 \geq$ \\
\hline & & Control & & 10 & $33 \pm 6$ & 40.0 & $24.4 \pm 2.1$ & $18 \pm 10$ & $7.4 \pm 1$ & \\
\hline Kamilla & 11 weeks & Endurance training & yes & 12 & $58 \pm 8$ & 58.3 & $27.4 \pm 3.1$ & $6 \pm 4$ & $6.9 \pm 0.9$ & $3.9 \leq$ \\
\hline $2018(40)$ & & $\begin{array}{l}\text { High-intensity } \\
\text { interval training }\end{array}$ & & 13 & $54 \pm 6$ & 53.8 & $28.1 \pm 3.5$ & $8 \pm 4$ & $6.8 \pm 0.8$ & $10 \geq$ \\
\hline & & Control & & 7 & $57 \pm 7$ & 71.4 & $28.0 \pm 3.5$ & $7 \pm 5$ & $7.0 \pm 1.15$ & \\
\hline $\begin{array}{l}\text { Angela } \\
2020(41)\end{array}$ & 12 weeks & $\begin{array}{l}\text { High-intensity } \\
\text { interval training }\end{array}$ & NA & 12 & $40.5 \pm 10.0$ & 50 & $29.0 \pm 2.1$ & $15.8 \pm 12.2$ & $8.63 \pm 0.66$ & $\begin{array}{l}3.9 \leq \\
10 \geq\end{array}$ \\
\hline & & Control & & 15 & $46.1 \pm 10.5$ & 67 & $31.6 \pm 3.4$ & $22.5 \pm 10.0$ & $8.37 \pm 0.71$ & \\
\hline
\end{tabular}

HbA1c, Hemoglobin A1c; BMI, body mass index; NA, not available.

-1.79 to $\left.2.51 \%, P=0.74, \mathrm{I}^{2}=92 \%\right)$ when compared to the control group.

When compared to the control group, physical activity was associated with a significant decrease in TAR (WMDs, $-3.61 \%$; $95 \% \mathrm{CI},-5.30$ to $\left.-1.92 \%, P<0.01, \mathrm{I}^{2}=0 \%\right)$ in patients with type 2 diabetes, while with no effect on TAR in patients with type 1 diabetes (Table 2 and Supplementary Figure S5). Physical activity was not associated with a significant change in TBR in patients with type 1 diabetes, or type 2 diabetes (Table 2 and Supplementary Figure S6). 


\section{Meta-Regression of the Associated Factors and TIR, MAGR, TAR, and TBR}

According to meta-regression analysis, patients with higher baseline BMI was associated with greater decrease in MAGE during physical activity $(\beta=-0.392,95 \% \mathrm{CI}:-0.710,-0.074)$. And patients with lower baseline $\mathrm{HbA1c}$ levels was associated with greater increase in TBR during physical activity $(\beta=-0.903,95 \%$ CI: $-1.550,-0.255$ ) (Table 3 and Supplementary Figures S7-S10).

\section{DISCUSSION}

By analyzing data from RCTs of physical activity treatment in patients with diabetes, we found that when compared with the control group, physical activity intervention was associated with significantly increased TIR and significantly decreased MAGE and TAR in patients with diabetes, but was not associated with an increase in TBR. Furthermore, patients with higher baseline BMI levels tended to have a greater decrease in MAGE during physical activities. Moreover, patients with lower baseline HbA1c levels showed a more significant increase in TBR during physical activities.

It was well known that physical activity treatment could improve glycemic control $(4,5)$, and our results further unveiled that physical activity might improve glycemic control by reducing the time that patients stay in hyperglycemic statues and increasing the time within the normal range. In addition to overall glycemic control, it also suggested that physical activity was associated with significantly decreased within-day glycemic variability. There were systemic reviews that also suggested that physical activity might be associated with a reduction in glycemic variability, but those reviews did not perform meta-analysis to synthesize the pooled effect of physical activity on glycemic variability and failed to conclude $(42,43)$. In this study, we took a step forward to quantitatively analyze the pooled effect of physical activity on glycemic variability and provided new evidence to the assumption that physical activity might reduce glycemic variability.

Concerns of hypoglycemia events have cast a shadow over the application of physical activity treatment in the clinical management of diabetes. And according to our analysis, generally speaking, physical activity would not significantly increase the time patients spent in hypoglycemia. However, we found a significant increase in TBR in patients with type 2 diabetes, and the sample size of type 1 diabetes was too small to conclude. Furthermore, patients with lower HbA1c levels tended to have more increments in TBR during physical activity. Hence, close glucose monitoring before, during, and after physical activity is crucial to preventing hypoglycemia, especially in patients with good glycemic control.

We also tried to explore which kind of patient was more suitable for physical activity treatment. Results from this study indicated that in type 2 diabetes, patients with higher baseline BMI level and short disease duration might get more reduction in glycemic variability through physical activity treatment. It might be assumed that physical activity may improve glycemic control by alleviating insulin resistance. At the early stage of type 2 diabetes, patients may have sufficient islet function, and insulin resistance tends to be the leading cause of hyperglycemia, especially in obese patients (44-46). Thus, these patients could benefit more from physical activity. However, no significant improvement in glycemic variability was found in patients with long disease duration or patients with type 1 diabetes, which might suggest that patients with poor islet function might have limited benefit in glycemic control from physical activity. Nevertheless, this hypothesis still needs further evidence to validate.

Several factors could potentially affect the effect of physical activity on glycemic variability. First of all, compensatory eating after physical activity would diminish the beneficial effect of physical activity. To evaluate the influence of compensatory eating on our results, we summarized the diet status of included studies (Table 1). According to the result, 11 over 13 included studies provided their participants with a standard diet during the experiment. Hence, in this study, compensatory eating after physical activity was unlikely to post a substantial influence on the beneficial effect of physical activity. Another important influencing factor was the adherence to the exercise plan. The mean adherence of patients in the included studies was summarized in Supplementary Table S2. Among 13 studies, 6 studies reported $99 \%-100 \%$ adherence of patients to the exercise plan; 1 study reported $65 \%-70 \%$ adherence to the exercise plan, and 6 studies did not report the adherence of patients. Thus, poor adherence of patients would probably affect the outcomes by lessening the beneficial effect of physical activity. The frequency and the intensity of physical activity would also alter the effect of physical activity on glycemic control (47). The detailed exercise plan of included studies was displayed in Supplementary Table S2. However, it was difficult to identify how the exercise frequency and intensity affected the effect of physical activity based on existing data. There were other characteristics, such as medication usage and comorbidities that might interfere with the glycemic control outcomes. Despite we attempted to extract and adjust these variables, they were not commonly reported in the studies. Further investigations were required to identify the influence of these variables on the effect of physical activity on glycemic variability.

Our study has its own contributions to the field. According to our knowledge, this was the first systematic review and metaanalysis to assess the relationship between physical activity and glycemic variability in patients with diabetes. Moreover, our results indicated that physical activity was associated with a significant reduction in glycemic variability, which might promote physical activity therapy in clinical practice. Several limitations should also be noted. Firstly, the sample size in type 1 diabetes was too small to draw a definite conclusion. Secondly, the definition of hypoglycemia and hyperglycemia was slightly different from trials. We summarized the definition of hypoglycemia and hyperglycemia of each trial in Table 1. Differences in the definition of targeted range might affect the 
TABLE 2 | Effect of physical activity on TIR, MAGE, TAR, and TBR.

\begin{tabular}{|c|c|c|c|c|c|c|}
\hline Group or Subgroup & No. of participants (physical activity/control) & WMDs & $95 \% \mathrm{Cl}$ of WMDs & $P$ value & $\mathbf{I}^{2}$ & $95 \% \mathrm{Cl}$ of $\mathrm{I}^{2}$ \\
\hline \multicolumn{7}{|c|}{ Effect of physical activity on TIR } \\
\hline Overall & 120/112 & $4.17 \%$ & $1.11 \%, 7.23 \%$ & $<0.01$ & $0 \%$ & $0 \%, 75 \%$ \\
\hline T1DM & $32 / 35$ & $3.87 \%$ & $-5.04 \%, 12.78 \%$ & 0.39 & $1 \%$ & $0 \%, 90 \%$ \\
\hline T2DM & $88 / 77$ & $4.21 \%$ & $0.95 \%, 7.46 \%$ & $<0.01$ & $0 \%$ & $0 \%, 90 \%$ \\
\hline \multicolumn{7}{|c|}{ Effect of physical activity on MAGE } \\
\hline Overall & $303 / 311$ & $-0.68 \mathrm{mmol} / \mathrm{L}$ & $-1.01 \mathrm{mmol} / \mathrm{L},-0.36 \mathrm{mmol} / \mathrm{L}$ & $<0.01$ & $78 \%$ & $66 \%, 86 \%$ \\
\hline $\mathrm{HbA} 1 \mathrm{c}<7 \%$ & $143 / 143$ & $-0.38 \mathrm{mmol} / \mathrm{L}$ & $-0.81 \mathrm{mmol} / \mathrm{L},-0.04 \mathrm{mmol} / \mathrm{L}$ & 0.08 & $60 \%$ & $9 \%, 83 \%$ \\
\hline $\mathrm{HbA} 1 \mathrm{c} \geq 7 \%$ & $160 / 168$ & $-1.13 \mathrm{mmol} / \mathrm{L}$ & $-1.44 \mathrm{mmol} / \mathrm{L},-0.82 \mathrm{mmol} / \mathrm{L}$ & $<0.01$ & $52 \%$ & $7 \%, 75 \%$ \\
\hline $\mathrm{BMl} \geq 30 \mathrm{~kg} / \mathrm{m}^{2}$ & $161 / 169$ & $-1.08 \mathrm{mmol} / \mathrm{L}$ & $-1.45 \mathrm{mmol} / \mathrm{L},-0.71 \mathrm{mmol} / \mathrm{L}$ & $<0.01$ & $68 \%$ & $37 \%, 84 \%$ \\
\hline $\mathrm{BMl}<30 \mathrm{~kg} / \mathrm{m}^{2}$ & $114 / 114$ & $-0.44 \mathrm{mmol} / \mathrm{L}$ & $-0.82 \mathrm{mmol} / \mathrm{L},-0.06 \mathrm{mmol} / \mathrm{L}$ & 0.02 & $0 \%$ & 0\%, 68\% \\
\hline Age $\leq 60$ years & $122 / 130$ & $-0.50 \mathrm{mmol} / \mathrm{L}$ & $-0.93 \mathrm{mmol} / \mathrm{L},-0.06 \mathrm{mmol} / \mathrm{L}$ & 0.03 & $0 \%$ & $0 \%, 66 \%$ \\
\hline Age $>60$ years & $181 / 181$ & $-0.77 \mathrm{mmol} / \mathrm{L}$ & $-1.18 \mathrm{mmol} / \mathrm{L},-0.36 \mathrm{mmol} / \mathrm{L}$ & $<0.01$ & $89 \%$ & $81 \%, 94 \%$ \\
\hline Male percentage $\leq 75 \%$ & 192/192 & $-0.80 \mathrm{mmol} / \mathrm{L}$ & $-1.19 \mathrm{mmol} / \mathrm{L},-0.42 \mathrm{mmol} / \mathrm{L}$ & $<0.01$ & $82 \%$ & $66 \%, 91 \%$ \\
\hline Male percentage $>75 \%$ & $111 / 119$ & $-0.58 \mathrm{mmol} / \mathrm{L}$ & -1.02 mmol/L, -0.14 mmol/L & $<0.01$ & $40 \%$ & $0 \%, 71 \%$ \\
\hline Disease duration $\geq 7.1$ years & $143 / 143$ & $-0.38 \mathrm{mmol} / \mathrm{L}$ & $-0.81 \mathrm{mmol} / \mathrm{L}, 0.04 \mathrm{mmol} / \mathrm{L}$ & 0.08 & $60 \%$ & $9 \%, 83 \%$ \\
\hline Disease duration $<7.1$ years & $160 / 168$ & $-1.13 \mathrm{mmol} / \mathrm{L}$ & $-1.44 \mathrm{mmol} / \mathrm{L},-0.82 \mathrm{mmol} / \mathrm{L}$ & $<0.01$ & $58 \%$ & $52 \%, 90 \%$ \\
\hline \multicolumn{7}{|c|}{ Effect of physical activity on TAR } \\
\hline Overall & $265 / 265$ & $-3.54 \%$ & $-5.12 \%,-1.88 \%$ & $<0.01$ & $0 \%$ & $0 \%, 49 \%$ \\
\hline T1DM & $32 / 35$ & $-1.43 \%$ & $-11.07 \%, 8.30 \%$ & 0.77 & $40 \%$ & $0 \%, 81 \%$ \\
\hline T2DM & $233 / 230$ & $-3.61 \%$ & $-5.30 \%,-1.92 \%$ & $<0.01$ & $0 \%$ & $0 \%, 52 \%$ \\
\hline \multicolumn{7}{|c|}{ Effect of physical activity on TBR } \\
\hline Overall & $95 / 87$ & $0.36 \%$ & $-1.79 \%, 2.51 \%$ & 0.74 & $92 \%$ & $87 \%, 95 \%$ \\
\hline T1DM & $32 / 35$ & $-0.89 \%$ & $-5.22 \%, 3.44 \%$ & 0.69 & $34 \%$ & 0\%, 78\% \\
\hline T2DM & $63 / 52$ & $0.69 \%$ & $-1.78 \%, 3.15 \%$ & 0.58 & $95 \%$ & $92 \%, 97 \%$ \\
\hline
\end{tabular}

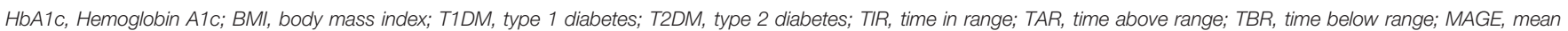
amplitude of glycemic excursion; WMDs, weighted mean differences; Cl, confidential interval.

absolute value of TIR, TAR, and TBR, which warrants caution in interpreting the results of this meta-analysis. Thirdly, the heterogeneity of studies included in the analysis of MAGE and TBR was high. We assumed two possible reasons for the

TABLE 3 | Meta-regression analysis for the associated factors and change in TIR, MAGE, TAR, and TBR.

\begin{tabular}{|c|c|c|}
\hline \multirow{2}{*}{$\begin{array}{l}\text { Variables } \\
\text { Time in range }\end{array}$} & \multicolumn{2}{|c|}{ Meta regression analysis } \\
\hline & $\beta$ & $95 \% \mathrm{Cl}$ \\
\hline Baseline $\mathrm{HbA} 1 \mathrm{c}$ & -0.015 & $-0.112,0.082$ \\
\hline Baseline BMI & -0.006 & $-0.170,0.158$ \\
\hline Baseline age & 0.005 & $-0.025,0.034$ \\
\hline Baseline male percentage & -0.009 & $-0.086,0.068$ \\
\hline Disease duration & -0.240 & $-0.864,0.385$ \\
\hline Time above range & $\beta$ & $95 \% \mathrm{Cl}$ \\
\hline Baseline $\mathrm{HbA} 1 \mathrm{c}$ & 0.358 & $-0.066,0.783$ \\
\hline Baseline BMI & 0.003 & $-0.101,0.106$ \\
\hline Baseline male percentage & -0.007 & $-0.016,0.003$ \\
\hline Disease duration & 0.028 & $-0.024,0.079$ \\
\hline Time below range & $\beta$ & $95 \% \mathrm{Cl}$ \\
\hline Baseline HbA1c & $-0.903^{\star}$ & $-1.550,-0.255$ \\
\hline Baseline BMI & -0.015 & $-0.689,0.660$ \\
\hline Baseline age & 0.040 & $-0.002,0.082$ \\
\hline Baseline male percentage & 0.030 & $-0.011,0.071$ \\
\hline Disease duration & -0.124 & $-0.267,0.019$ \\
\hline MAGE & $\beta$ & $95 \% \mathrm{Cl}$ \\
\hline Baseline $\mathrm{HbA} 1 \mathrm{c}$ & -2.347 & $-5.482,0.789$ \\
\hline Baseline BMI & $-0.392^{*}$ & $-0.710,-0.074$ \\
\hline Baseline age & -0.058 & $-0.205,0.088$ \\
\hline Baseline male percentage & 0.021 & $-0.017,0.059$ \\
\hline Disease duration & 0.008 & $-0.325,0.342$ \\
\hline
\end{tabular}

* $p$ value < 0.05; HbA1c, Hemoglobin A1c; BMI, body mass index; TIR, time in range; TAR, time above range; TBR, time below range; MAGE, mean amplitude of glycemic excursion; $\mathrm{Cl}$, confidential interval. heterogeneity in this study. The first one was the diversity in baseline characteristics of the included patients among trials. In subgroup analysis, the heterogeneity of MAGE decreased when stratified by baseline age and baseline BMI level. This phenomenon might partly confirm our consumption. The second one might be the variable types of physical activity and different intensity of physical activity taking in the included studies. We summarized the detailed exercise information and the compliance of participants in Supplementary Table S2. Differences in the type and intensity of physical activity would probably introduce heterogeneity to the analysis. Finally, most studies included in the analysis only report the glycemic data within 24 hours. Hence, it was difficult to access the between-day glycemic variability in this study. In the future, studies with a larger sample size especially for patients with type 1 diabetes, with longer intervention duration, with well designs to control the aforementioned confounding factors are required to further explore the effect of physical activity on glycemic variability.

\section{CONCLUSIONS}

According to our study, physical activity intervention was significantly associated with decreased glycemic variability in patients with diabetes. Patients with higher BMI level and shorter disease duration might benefit more from physical activity therapy. Overall, physical activity intervention was not associated with increased time in hypoglycemia. However, hypoglycemic events related to physical activity treatment still warranted caution, especially in patients with intensive glycemic control. 


\section{DATA AVAILABILITY STATEMENT}

The original contributions presented in the study are included in the article/Supplementary Material. Further inquiries can be directed to the corresponding authors.

\section{AUTHOR CONTRIBUTIONS}

XZ, XC, JC, LZhan, and LJ conceptualized this study and designed the systematic review protocol. XZ and LZhao performed the study selection and data extraction. XZ, SH, FL, and XC performed the statistical analyses. XZ, CL, and XC prepared the outlines and wrote the manuscript. All authors contributed to the article and approved the submitted version.

\section{FUNDING}

This work was supported by the National Natural Science Foundation of China (No.81970698 and No.81970708), Beijing

\section{REFERENCES}

1. Gebreslassie M, Sampaio F, Nystrand C, Ssegonja R, Feldman I. Economic Evaluations of Public Health Interventions for Physical Activity and Healthy Diet: A Systematic Review. Prev Med (Baltim) (2020) 136:106100. doi: 10.1016/j.ypmed.2020.106100

2. Warburton DER, Bredin SSD. Health Benefits of Physical Activity. Curr Opin Cardiol (2017) 32:541-56. doi: 10.1097/HCO.0000000000000437

3. Avery L, Flynn D, Dombrowski SU, van Wersch A, Sniehotta FF, Trenell MI. Successful Behavioural Strategies to Increase Physical Activity and Improve Glucose Control in Adults With Type 2 Diabetes. Diabetes Med (2015) 32:1058-62. doi: 10.1111/dme.12738

4. Umpierre D. Physical Activity Advice Only or Structured Exercise Training and Association With HbA 1c Levels in Type 2 Diabetes. JAMA (2011) 305:1790. doi: 10.1001/jama.2011.576

5. Borror A, Zieff G, Battaglini C, Stoner L. The Effects of Postprandial Exercise on Glucose Control in Individuals With Type 2 Diabetes: A Systematic Review. Sport Med (2018) 48:1479-91. doi: 10.1007/s40279-018-0864-x

6. Church TS, Blair SN, Cocreham S, Johannsen N, Johnson W, Kramer K, et al. Effects of Aerobic and Resistance Training on Hemoglobin A 1c Levels in Patients With Type 2 Diabetes. JAMA (2010) 304:2253. doi: 10.1001/ jama.2010.1710

7. Dunstan DW, Thorp AA, Healy GN. Prolonged Sitting. Curr Opin Cardiol (2011) 26:412-9. doi: 10.1097/HCO.0b013e3283496605

8. Dempsey PC, Larsen RN, Sethi P, Sacre JW, Straznicky NE, Cohen ND, et al. Benefits for Type 2 Diabetes of Interrupting Prolonged Sitting With Brief Bouts of Light Walking or Simple Resistance Activities. Diabetes Care (2016) 39:964-72. doi: 10.2337/dc15-2336

9. American Diabetes Association 5. Facilitating Behavior Change and WellBeing to Improve Health Outcomes: Standards of Medical Care in Diabetes2021. Diabetes Care (2021) 44:S53-72. doi: 10.2337/dc21-S005

10. Cosentino F, Grant PJ, Aboyans V, Bailey CJ, Ceriello A, Delgado V, et al. ESC Guidelines on Diabetes, Pre-Diabetes, and Cardiovascular Diseases Developed in Collaboration With the EASD. Eur Heart J (2020) 41:255-323. doi: 10.1093/eurheartj/ehz486

11. Sigal RJ, Armstrong MJ, Bacon SL, Boulé NG, Dasgupta K, Kenny GP, et al. Physical Activity and Diabetes. Can J Diabetes (2018) 42:S54-63. doi: 10.1016/ j.jcjd.2017.10.008

12. Bachmann S, Hess M, Martin-Diener E, Denhaerynck K, Zumsteg U. Nocturnal Hypoglycemia and Physical Activity in Children With Diabetes:
Natural Science Foundation (No.7202216), and Fundamental Research Funds for the China Institute of Sport Science (Project 15-22). The funding agencies had no roles in the study design, data collection or analysis, decision to publish, or manuscript preparation.

\section{ACKNOWLEDGMENTS}

We thank the doctors, nurses, and technicians from the Department of Endocrinology and Metabolism study in Peking University People's Hospital for their help in the study.

\section{SUPPLEMENTARY MATERIAL}

The Supplementary Material for this article can be found online at: https://www.frontiersin.org/articles/10.3389/fendo.2021.767152/ full\#supplementary-material
New Insights by Continuous Glucose Monitoring and Accelerometry. Diabetes Care (2016) 39:e95-6. doi: 10.2337/dc16-0411

13. Metcalf KM, Singhvi A, Tsalikian E, Tansey MJ, Zimmerman MB, Esliger DW, et al. Effects of Moderate-To-Vigorous Intensity Physical Activity on Overnight and Next-Day Hypoglycemia in Active Adolescents With Type 1 Diabetes. Diabetes Care (2014) 37:1272-8. doi: 10.2337/dc13-1973

14. Quirk H, Blake H, Tennyson R, Randell TL, Glazebrook C. Physical Activity Interventions in Children and Young People With Type 1 Diabetes Mellitus: A Systematic Review With Meta-Analysis. Diabetes Med (2014) 31:1163-73. doi: 10.1111/dme.12531

15. Turner D, Gray BJ, Luzio S, Dunseath G, Bain SC, Hanley S, et al. Similar Magnitude of Post-Exercise Hyperglycemia Despite Manipulating Resistance Exercise Intensity in Type 1 Diabetes Individuals. Scand J Med Sci Sports (2016) 26:404-12. doi: 10.1111/sms.12472

16. Guelfi KJ, Jones TW, Fournier PA. The Decline in Blood Glucose Levels Is Less With Intermittent High-Intensity Compared With Moderate Exercise in Individuals With Type 1 Diabetes. Diabetes Care (2005) 28:1289-94. doi: 10.2337/diacare.28.6.1289

17. Gordon BA, Bird SR, MacIsaac RJ, Benson AC. Does a Single Bout of Resistance or Aerobic Exercise After Insulin Dose Reduction Modulate Glycaemic Control in Type 2 Diabetes? A Randomised Cross-Over Trial. J Sci Med Sport (2016) 19:795-9. doi: 10.1016/j.jsams.2016.01.004

18. Frontoni S, Di Bartolo P, Avogaro A, Bosi E, Paolisso G, Ceriello A. Glucose Variability: An Emerging Target for the Treatment of Diabetes Mellitus. Diabetes Res Clin Pract (2013) 102:86-95. doi: 10.1016/j.diabres.2013.09.007

19. Bonke FC, Donnachie E, Schneider A, Mehring M. Association of the Average Rate of Change in HbAlc With Severe Adverse Events: A Longitudinal Evaluation of Audit Data From the Bavarian Disease Management Program for Patients With Type 2 Diabetes Mellitus. Diabetologia (2016) 59:286-93. doi: 10.1007/s00125-015-3797-z

20. Wan EYF, Fung CSC, Fong DYT, Lam CLK. Association of Variability in Hemoglobin Alc With Cardiovascular Diseases and Mortality in Chinese Patients With Type 2 Diabetes Mellitus - A Retrospective Population-Based Cohort Study. J Diabetes Complications (2016) 30:1240-7. doi: 10.1016/ j.jdiacomp.2016.05.024

21. Wightman SS, Sainsbury CAR, Jones GC. Visit-To-Visit HbA1c Variability and Systolic Blood Pressure (SBP) Variability Are Significantly and Additively Associated With Mortality in Individuals With Type 1 Diabetes: An Observational Study. Diabetes Obes Metab (2018) 20:1014-7. doi: 10.1111/ dom.13193 
22. Suh S, Kim JH. Glycemic Variability: How Do We Measure It and Why Is It Important? Diabetes Metab J (2015) 39:273. doi: 10.4093/dmj.2015.39. 4.273

23. Kovatchev B, Cobelli C. Glucose Variability: Timing, Risk Analysis, and Relationship to Hypoglycemia in Diabetes. Diabetes Care (2016) 39:502-10. doi: $10.2337 / \mathrm{dc} 15-2035$

24. Battelino T, Danne T, Bergenstal RM, Amiel SA, Beck R, Biester T, et al. Clinical Targets for Continuous Glucose Monitoring Data Interpretation: Recommendations From the International Consensus on Time in Range. Diabetes Care (2019) 42:1593-603. doi: 10.2337/dci19-0028

25. Cumpston M, Li T, Page MJ, Chandler J, Welch VA, Higgins JP, et al. Updated Guidance for Trusted Systematic Reviews: A New Edition of the Cochrane Handbook for Systematic Reviews of Interventions. Cochrane Database Syst Rev (2019). doi: 10.1002/14651858.ED000142

26. Guyatt GH, Oxman AD, Vist GE, Kunz R, Falck-Ytter Y, Alonso-Coello P, et al. GRADE: An Emerging Consensus on Rating Quality of Evidence and Strength of Recommendations. BMJ (2008) 336:924-6. doi: 10.1136/ bmj.39489.470347.AD

27. Higgins JPT, Thompson SG. Quantifying Heterogeneity in a Meta-Analysis. Stat Med (2002) 21:1539-58. doi: 10.1002/sim.1186

28. Ioannidis JPA, Patsopoulos NA, Evangelou E. Uncertainty in Heterogeneity Estimates in Meta-Analyses. BMJ (2007) 335:914-6. doi: 10.1136/bmj.39343. 408449.80

29. Dempsey PC, Blankenship JM, Larsen RN, Sacre JW, Sethi P, Straznicky NE, et al. Interrupting Prolonged Sitting in Type 2 Diabetes: Nocturnal Persistence of Improved Glycaemic Control. Diabetologia (2017) 60:499-507. doi: $10.1007 / \mathrm{s} 00125-016-4169-\mathrm{z}$

30. Haxhi J, Leto G, di Palumbo AS, Sbriccoli P, Guidetti L, Fantini C, et al. Exercise at Lunchtime: Effect on Glycemic Control and Oxidative Stress in Middle-Aged Men With Type 2 Diabetes. Eur J Appl Physiol (2016) 116:57382. doi: 10.1007/s00421-015-3317-3

31. Rees JL, Chang CR, François ME, Marcotte-Chénard A, Fontvieille A, Klaprat ND, et al. Minimal Effect of Walking Before Dinner on Glycemic Responses in Type 2 Diabetes: Outcomes From the Multi-Site E-PAraDiGM Study. Acta Diabetol (2019) 56:755-65. doi: 10.1007/s00592-019-01358-x

32. Li Z, Hu Y, Yan R, Li H, Zhang D, Li F, et al. Twenty Minute ModerateIntensity Post-Dinner Exercise Reduces the Postprandial Glucose Response in Chinese Patients with Type 2 Diabetes. Med Sci Monit (2018) 24:7170-7. doi: 10.12659/MSM.910827

33. Metcalfe RS, Fitzpatrick B, Fitzpatrick S, McDermott G, Brick N, McClean C, et al. Extremely Short Duration Interval Exercise Improves 24-h Glycaemia in Men With Type 2 Diabetes. Eur J Appl Physiol (2018) 118:2551-62. doi: 10.1007/s00421-018-3980-2

34. Karstoft K, Clark MA, Jakobsen I, Müller IA, Pedersen BK, Solomon TPJ, et al. The Effects of 2 Weeks of Interval vs Continuous Walking Training on Glycaemic Control and Whole-Body Oxidative Stress in Individuals With Type 2 Diabetes: A Controlled, Randomised, Crossover Trial. Diabetologia (2017) 60:508-17. doi: 10.1007/s00125-016-4170-6

35. Myette-Côté E, Terada T, Boulé NG. The Effect of Exercise With or Without Metformin on Glucose Profiles in Type 2 Diabetes: A Pilot Study. Can J Diabetes (2016) 40:173-7. doi: 10.1016/j.jcjd.2015.08.015

36. Terada T, Wilson BJ, Myette-Côté E, Kuzik N, Bell GJ, McCargar LJ, et al. Targeting Specific Interstitial Glycemic Parameters With High-Intensity Interval Exercise and Fasted-State Exercise in Type 2 Diabetes. Metabolism (2016) 65:599-608. doi: 10.1016/j.metabol.2016.01.003

37. Blankenship JM, Chipkin SR, Freedson PS, Staudenmayer J, Lyden K, Braun B. Managing Free-Living Hyperglycemia With Exercise or Interrupted Sitting in Type 2 Diabetes. J Appl Physiol (2019) 126:616-25. doi: 10.1152/japplphysiol.00389.2018
38. Munan M, Dyck RA, Houlder S, Yardley JE, Prado CM, Snydmiller G, et al. Does Exercise Timing Affect 24-Hour Glucose Concentrations in Adults With Type 2 Diabetes? A Follow Up to the Exercise-Physical Activity and Diabetes Glucose Monitoring Study. Can J Diabetes (2020) 44:711-8.e1. doi: 10.1016/ j.jcjd.2020.05.012

39. Reddy R, Wittenberg A, Castle JR, El Youssef J, Winters-Stone K, Gillingham $\mathrm{M}$, et al. Effect of Aerobic and Resistance Exercise on Glycemic Control in Adults With Type 1 Diabetes. Can J Diabetes (2019) 43:406-14.e1. doi: $10.1016 /$ j.jcjd.2018.08.193

40. Winding KM, Munch GW, Iepsen UW, Van Hall G, Pedersen BK, Mortensen SP. The Effect on Glycaemic Control of Low-Volume High-Intensity Interval Training Versus Endurance Training in Individuals With Type 2 Diabetes. Diabetes Obes Metab (2018) 20:1131-9. doi: 10.1111/dom.13198

41. Lee AS, Johnson NA, McGill MJ, Overland J, Luo C, Baker CJ, et al. Effect of High-Intensity Interval Training on Glycemic Control in Adults With Type 1 Diabetes and Overweight or Obesity: A Randomized Controlled Trial With Partial Crossover. Diabetes Care (2020) 43:2281-8. doi: 10.2337/dc20-0342

42. Bennetsen SL, Feineis CS, Legaard GE, Lyngbæk MPP, Karstoft K, RiedLarsen M. The Impact of Physical Activity on Glycemic Variability Assessed by Continuous Glucose Monitoring in Patients With Type 2 Diabetes Mellitus: A Systematic Review. Front Endocrinol (Lausanne) (2020) 11:486. doi: $10.3389 /$ fendo. 2020.00486

43. von Oetinger GA, Trujillo G LM, Soto IN. Impacto De La Actividad Física En La Variabilidad Glucémica En Personas Con Diabetes Mellitus Tipo 2. Rehabilitación (2021) 55(4):282-90. doi: 10.1016/j.rh.2020.11.004

44. Gallwitz B, Kazda C, Kraus P, Nicolay C, Schernthaner G. Contribution of Insulin Deficiency and Insulin Resistance to the Development of Type 2 Diabetes: Nature of Early Stage Diabetes. Acta Diabetol (2013) 50:39-45. doi: 10.1007/s00592-011-0319-4

45. Taylor R. Type 2 Diabetes: Etiology and Reversibility. Diabetes Care (2013) 36:1047-55. doi: $10.2337 / \mathrm{dc} 12-1805$

46. Pearson ER. Type 2 Diabetes: A Multifaceted Disease. Diabetologia (2019) 62:1107-12. doi: 10.1007/s00125-019-4909-y

47. Umpierre D, Ribeiro PAB, Schaan BD, Ribeiro JP. Volume of Supervised Exercise Training Impacts Glycaemic Control in Patients With Type 2 Diabetes: A Systematic Review With Meta-Regression Analysis. Diabetologia (2013) 56:242-51. doi: 10.1007/s00125-012-2774-z

Conflict of Interest: LJ has received fees for lecture presentations and for consulting from Merck, Metabasis, AstraZeneca, MSD, Novartis, Roche, Eli Lilly, SanofiAventis and Takeda.

The remaining authors declare that the research was conducted in the absence of any commercial or financial relationships that could be construed as a potential conflict of interest.

Publisher's Note: All claims expressed in this article are solely those of the authors and do not necessarily represent those of their affiliated organizations, or those of the publisher, the editors and the reviewers. Any product that may be evaluated in this article, or claim that may be made by its manufacturer, is not guaranteed or endorsed by the publisher.

Copyright (c) 2021 Zhu, Zhao, Chen, Lin, Lv, Hu, Cai, Zhang and Ji. This is an openaccess article distributed under the terms of the Creative Commons Attribution License (CC BY). The use, distribution or reproduction in other forums is permitted, provided the original author(s) and the copyright owner(s) are credited and that the original publication in this journal is cited, in accordance with accepted academic practice. No use, distribution or reproduction is permitted which does not comply with these terms. 